\title{
Design and Implementation of Automated Ankle Foot Orthosis for Foot Drop Patients Using Gait Cycle EMG Analysis
}

\author{
Md. Mamunoor Islam", Md. Humayun Kabir ${ }^{*}$, Quazi Delwar Hossain* \\ ${ }^{\#}$ Department of Electrical, Electronics and Telecommunication Engineering , Dhaka International University, \\ 66, Green Road, Dhaka, 1205, Bangladesh \\ E-mail: md.mamunoor.islam.bd@gmail.com \\ *Department of Eelctrical and Electronic Engineering, Chittagong University of Engineering and Technology, \\ Chittagong, 4349, Bangladesh \\ E-mail:humayun1202041@gmail.com,quazi@cuet.ac.bd
}

\begin{abstract}
Foot drop is known as gait abnormality in which the dropping of the forefoot happens due to the weakness of Tibialis Anterior Muscle for the damage of the common fibular nerve in the anterior portion of the lower leg. In this research, those patients are considered who have foot drop for Guillain-Barré syndrome (GBS). GBS is a peripheral nerve disorder for which bilateral foot drop happens to the patients. So, the aim of this research is to develop an automated Ankle Foot Orthosis (AFO) which will aid the GBS patients in their gait cycle while walking. For the development of this AFO, an EMG analysis has been conducted on both normal people (20 persons, Male 20-45 years) and GBS patients (10 patients, Male 20-45 years) and compared to find out the deviation of the patient's one from the normal people. The findings of the EMG study show that the stance phase of the gait cycle is not affected by the GBS as correlation coefficient values are in between 0.95 to 1 where the swing phase very much deviates from the normal pattern as the coefficient values are in between 0.6 to 0.7 as well as short swing phase and no heel strike during walking. Considering these, automated AFO has been developed and implemented to test the feasibility and effectiveness on patients. The experimental results show that the effect of GBS on swing phase can be lessened as the value of correlation coefficient increases to 0.85 to 0.9 with long swing phase and proper heel strike on terminal swing phase.
\end{abstract}

Keywords - Foot drop; GBS; Automated AFO; Gait; EMG.

\section{INTRODUCTION}

Foot drop is generally an indication of a greater problem, not a disease which can be categorized by impaired ability to raise the toes from the ankle. The effect of foot drop may last temporarily or permanently depending on the level of muscle weakness and it can also occur in one or both feet. It is mainly caused by neurological disorders such as central nerve disorder (Stroke, Multiple sclerosis, Cerebral palsy etc.) and peripheral nerve disorder (Guillain-Barré syndrome etc.) and rarely occurs for muscular disorders. The main problem happened by foot drop syndrome is the abnormality in the human gait cycle. As there are two main phases such as stance phase and swing phase of the gait cycle, foot drop mostly affects the swing phase which makes difficult for foot drop patients to walk in a proper manner.

Bilateral foot drop is a very common scenario for Guillain-Barré syndrome (GBS) patients. Guillain-Barré syndrome (GBS) is defined as a rapid-onset muscle weakness which is caused by the immune system damaging the peripheral nervous system. The preliminary indications are typically pain along with muscle weakness which begins in the feet and hands and spread over to the arms and upper body with both sides being involved for GBS patients [1]. Children and young adults are less affected than elders and the risk factor increases by $20 \%$ for every decade of life [2]. Men are more in risk position than women for developing GBS as the relative risk for men is 1.78 compared to women [3]. A GBS patient with foot drop faces difficulty while walking on his or her heels because he is unable to lift the front of the foot off the ground. So, Ankle Foot Orthosis (AFO) is used that encumbers the ankle and foot to control position and motion of the ankle, to compensate for weakness, or to correct deformities for foot drop. AFO is the most commonly used Orthosis, making up about $26 \%$ of all Orthosis provided in the United States [1]. But the AFOs which are available for the treatment doesn't have any automated and dynamic facility as there are no automated 
movements by providing ankle angle of different phases of the gait cycle.

So, the aim of this research is to design an automated Ankle Foot Orthosis for the drop foot patients of GuillainBarré syndrome (GBS) type that will aid them providing required angle while walking to correct the gait cycle pattern. As GBS patients have bilateral foot drop, electromyography operation is performed on both legs and will be compared with the normal standard EMG graph to differentiate the deviation from the standard ones. Hence, a practical prototype of automated Ankle Foot Orthosis is developed and implemented on patients and the performance is analyzed by EMG analysis of Tibialis Anterior muscle on whole gait cycle.

Numerous approaches have been made both in design and implementation sections to solve the foot drop syndrome. Ankle Foot Orthosis has been used for foot drop correction mostly in larger scale. As there are lots of complexity and deformity which can happen for a drop foot patient, the main task is to keep the foot in normal position by external aid device. Several designs have been proposed such as a model of an AFO for correction of foot abnormality has been designed in 2011 where it was tried to assist for recovering the foot abnormality but there was no implementation and performance analysis of that design [4]. In 2011, another design of a dorsiflexion assisted brace has been proposed where a prototype AFO has been implemented which was rubber splint styled in the shape of a catapult, made of discarded car rubber tubes attached to the frame of the fixator. But the whole design was very bulky and not patient friendly. The angle was provided by the use of rubber which was not reliable at all [5]. Then there are also lots of approaches made on developing dynamic AFO such as an automated and dynamic AFO was designed where strips were used to provide dorsiflexion angle for patients walking in the gait cycle. But the system was also not reliable as no angle measurement was done. So, proper rehabilitation was not meant to be achieved [6-10].

In 2012, a new active system AFO was proposed where a mechanism was showed to control actuator movement using force sensor. The method to control the actuator was based on real-time approach where the input was directly received from foot and transferred to output actuator movement. Flexi force sensors have been chosen as an input data by receiving force from foot patient. But the whole work was limited to the force sensor implementation only and there was only prototype implementation of that new AFO [11]. In 2011, another stiffness-adjustable ankle-foot orthosis was designed for patients whose stiffness was adjustable using commercially available oil-damper joints, and it was demonstrated the potential capability in investigating the effects of altering AFO stiffness on gait. The EAFO would be useful in investigating the influence of the stiffness of an AFO on gait as an orthotic treatment to achieve a better overall improvement in gait. But several parameters would affect the stiffness of thermoplastic AFO. It was bulkier and heavier compared to general AFO [12]. Earlier in 2010, another polypropylene AFO was proposed to overcome drop foot gait in central neurological patients where the main purpose was to assess the functional effects and mechanical contribution of AFO prescribed to overcome drop-foot gait.
The AFO was sufficiently stiff to effectively support the foot in swing, without hampering the ankle during stance. For the whole group, there was a significant improvement in walking speed and energy cost (12\%). However, the AFO had no functional benefit in terms of a reduced energy cost of walking for three patients, who coherently demonstrated no pathological plantar flexion during swing without their AFO [13]. In 2015, a design of a quasi-passive 3 DOFs ankle-foot wearable rehabilitation orthosis was proposed. The quasi-passive 3 DOFs ankle-foot wearable orthosis was designed based on kinematics and dynamics analysis of the ankle joint. Ankle joint trajectory and dynamic characteristics like those of natural gait could be obtained by the combination of passive energy storage and additional power complement. In terms of function, the orthosis had shock absorption and low energy consumption [14].

In 2017, another Ankle stretching rehabilitation machine has been developed for equinovarus where automation of eversion and flexion control has been achived. But the whole structure is very bulky and only developed for static rehabilitation process[15]. Another design of a pressure sensitive Ankle-Foot Orthosis has been proposed in 2017 for FES-aided gait training which lacks real patients involvements [16]. In 2018, another development of an Ankle-Foot Orthosis has ben proposed which provides support for Flaccid Paretic Plantarflexor and Dorsiflexor Muscles. This design also requires practical implementation and patients involvements [17]. Nowadays, fixed AFOs are generally used for patients which are constructed of lightweight polypropylene-based plastic in the shape of an "L", with the upright portion behind the calf and the lower portion running under the foot. They are attached to the calf with a strap and are made to fit inside accommodative shoes. This AFO is widely used to control position and motion of the ankle, to compensate for weakness and to recover deformities like foot drop. But as the structure is mainly fixed, there is no angle availability in the foot drop brace which is available in the market.

\section{MATERIAL AND METHOD}

This research is based on Electromyography (EMG) analysis. For a foot drop patient, the Tibialis Anterior (TA) muscle is no longer capable enough for contraction to function dorsiflexion operation which is to uplift the forefoot. So, the gait cycle has been affected by foot drop. To find out the problem in phases of the gait cycle, the EMG analysis has been performed which shows the deviations from the normal gait EMG pattern. At first, normal people (20 persons, Male 20-45 years) gait cycle EMG data of TA muscle have been recorded as well as foot drop patients. From these two graphs, the differences and deviations have been identified for foot drop syndrome.

In EMG analysis, raw EMG signal of the whole gait cycle is recorded through surface electrode and then the signal is conditioned and rectified and lastly, the envelope of the EMG signal has been extracted. After the findings of the affected phases of the gait cycle, an automated and dynamic ankle foot Orthosis has been designed which provides the required angle in the affected phases of gait cycle while walking. The proposed AFO provides angle using a high 
torque servo motor ( 0 to 180 degree) according to the standard angle chart of gait cycle for any human

\section{A. EMG Device development}

For extracting the surface EMG signal, an EMG signal extraction device has been developed in this project. The surface EMG signal has been collected by surface EMG electrode and recorded into computer at the same time through USB cable. $\mathrm{Ag} / \mathrm{AgCl}$ surface electrode has been used to capture EMG voltage from the skin. The electrode is based on gel so that motion artifact can be considered less effect on EMG signal acquisition. This EMG signal has been filtered, amplified and rectified by myoware muscle sensor device [18]. After that the enveloped EMG signal is transferred to computer using serial communication by USB cable. The block diagram of EMG extraction device has been shown in Fig. 1.

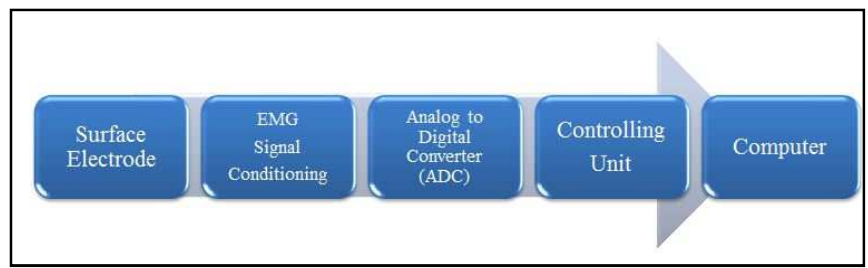

Fig. 1. Block Diagram of EMG device Development

\section{B. Development of Automated Ankle Foot Orthosis}

An automated and dynamic ankle foot Orthosis is designed that will provide the required angle in the affected phases of gait cycle while walking. The angle will be provided according to the standard angle chart of gait cycle for any human. The proposed AFO provides angle using high torque servo motor (ASME-03B) which can provide angle from 0 to 180 degrees. As the heel strike and toe off are the main functions in gait cycle, Force resistive sensor has been used to sense those functions. This force transducer output is sent to controlling unit through AD converter. And finally, the controlling unit provides the required angle in required affected phases of gait cycle. The block diagram of automated AFO is shown in Fig. 2.

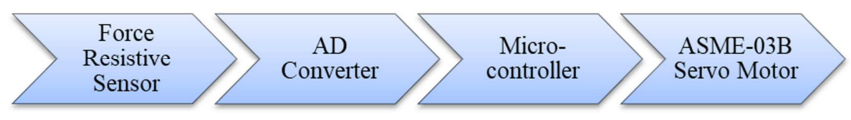

Fig. 2. Block diagram of Automated Ankle Foot Orthosis

As the gait cycle movement is dependent on heel strike, the heel pressure can be considered a vital parameter to developed this automated AFO. This heel force is measured by using force resistive sensor. When the heel pressure is there, the force sensor will sense it and transfer the information to $\mathrm{AD}$ converter. The $\mathrm{AD}$ converter converts the analog voltage into digital value. In this project, 10bit AD converter has been used when 5 volts is divided into 1024 digital voltage level. The digital voltage level is then transferred to micro controlling unit. The microcontroller gives the voltage pulse to servo motor unit which provides the actuating angle. The required actuating angle value has been set previously. This angle pulls the foot towards the shin and performs the dorsiflexion operation in swing phase. When the heel again strikes the floor, it provides another information to the controlling unit and the microcontroller again provides the pulse to servo motor and the angle that is previously given is taken back and the foot comes to the neutral position again.

\section{RESULTS AND DISCUSSION}

To develop the automated AFO, first EMG signal analysis is required. An EMG signal extraction device has been developed at first. In this project, gait cycle EMG signal of normal people and GBS patients has been compared to find the difference between two gait cycles. And finally, the automated AFO has been developed and implemented according the EMG analysis.

\section{A. EMG data extraction of Normal people}

To compare the gait cycle of GBS patient gait cycle with the standard one, first gait cycle EMG of Tibialis anterior (TA) muscle for normal people has been collected. The selection criteria were the person must be male and the age range must be $20-45$ years. We have taken around 20 normal people EMG data of a gait cycle and finally averaged them to find out the standard one. This average standard graph has been compared to all the patients gait cycle EMG. Fig.3 shows the implementation of EMG signal extraction of normal person.
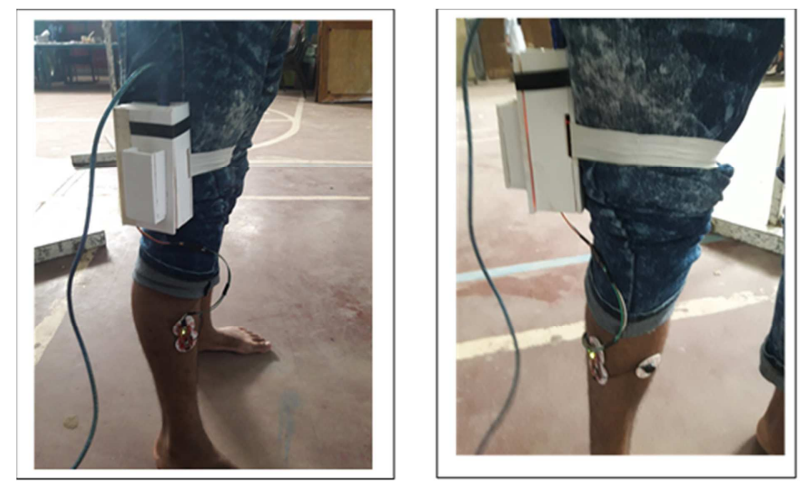

Fig. 3. Implementation of EMG device on normal people

The EMG amplified voltage has been transferred simultaneously to the computer for recording purpose. An USB cable is used to perform by serial data communication. Numerous gait cycle EMG data are recorded from every person (Fig. 4) and then all the gait cycle data has been averaged to find out the standard EMG pattern of TA muscle which is shown in Fig.5.

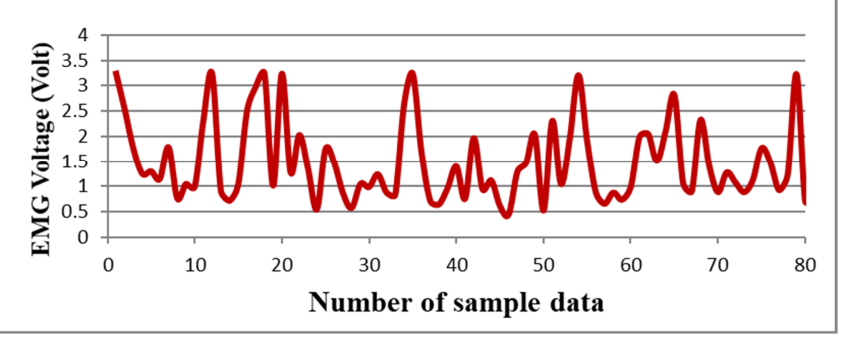

Fig. 4. Gait Cycle Electromyography of numerous gait cycles 


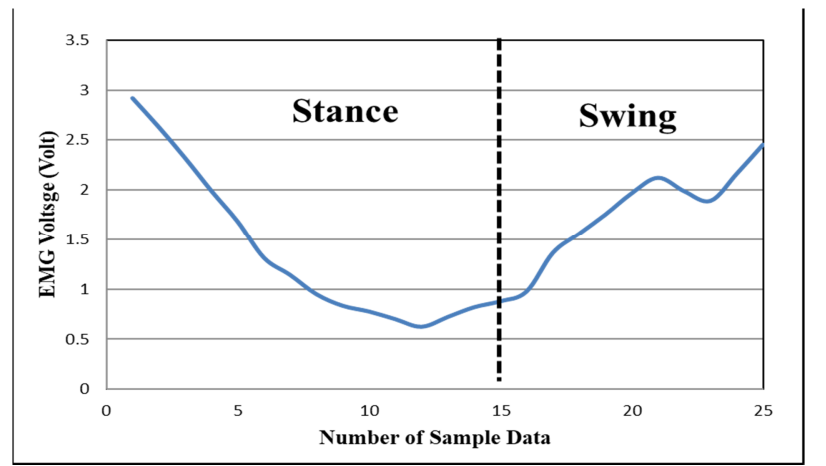

Fig. 5. Averaged Gait Cycle Electromyograph of TA Muscle

\section{B. EMG extraction of GBS Patients}

To compare with the standard average graph, GBS patients gait cycle EMG data has been extracted. The selection criteria were the same as person must be male and age range must be 20 to 45 years. The patients must have a gait to walk at least $4 / 5$ gait cycles.
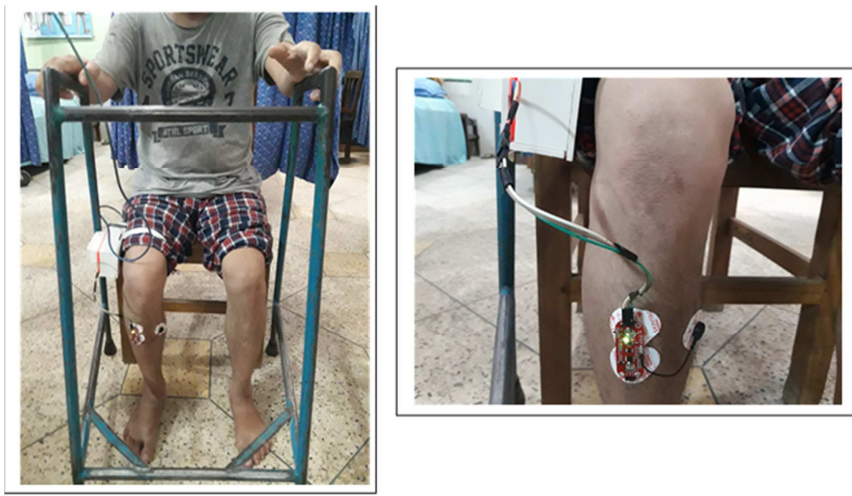

Fig. 6. EMG data extraction on GBS patient (Right Leg)

The EMG data has been extracted from both right leg and left leg as GBS patients have symmetrical foot drop on both legs which can be observed from Fig. 6 and Fig.7. The patient's EMG graph has been compared with the standard EMG graph to find out the effect of GBS on gait in Fig.8.
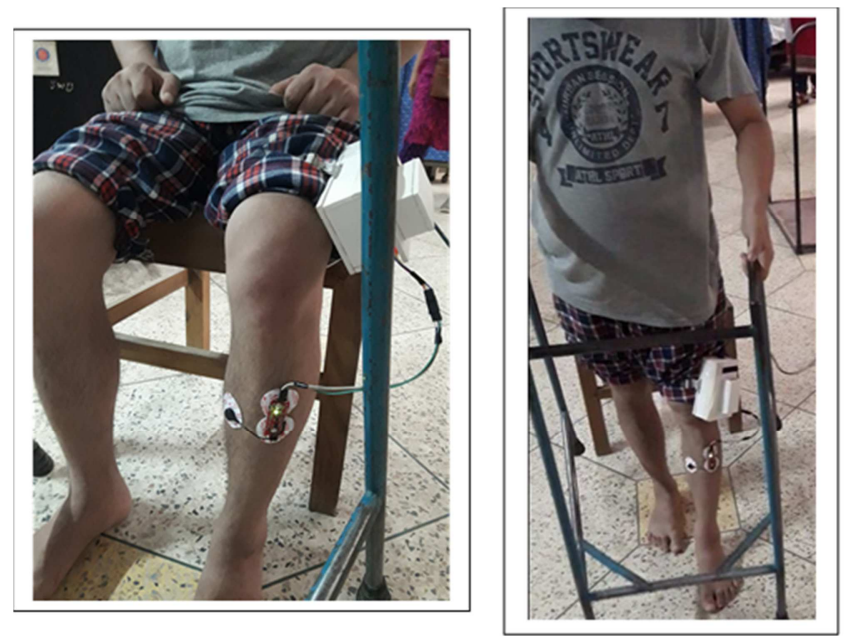

Fig. 7. EMG data extraction on GBS patient (Left Leg)

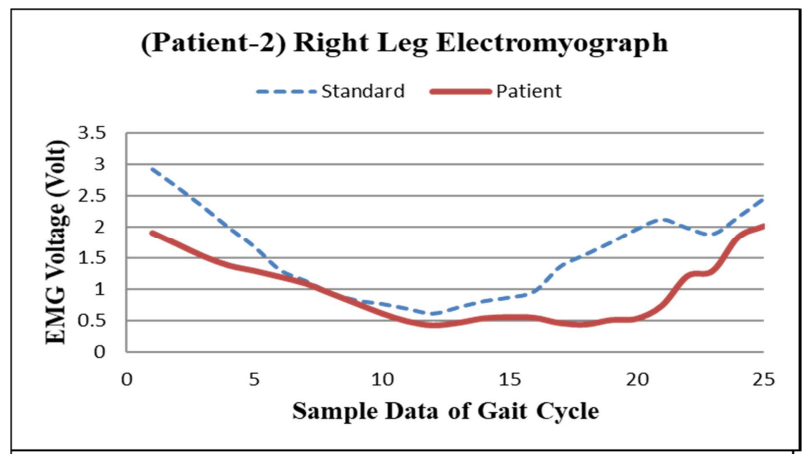

(Patient-2) Left Leg Electromyograph

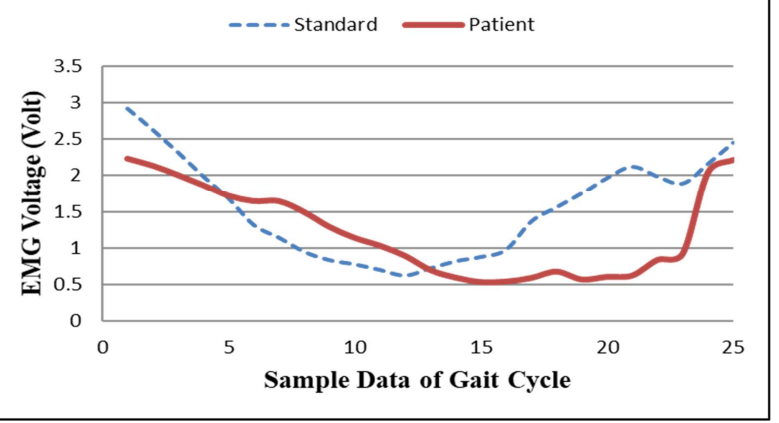

Fig. 8. Right and Left Leg EMG of Patient-2

From the comparison between standard graph and patient EMG graph, it is obtained that the gait cycles of GBS patients are affected by GBS foot drop. The comparison has been done by finding correlation coefficient between two graphs and the trend of the graph has been analyzed on stance phase, swing phase and whole graph. The comparison between standard and patient (5) data has been shown in TABLE I.

TABLE I

COMPARISON DATA BETWEEN STANDARD DATA AND PATIENT DATA

\begin{tabular}{|c|c|c|c|c|}
\hline $\begin{array}{c}\text { Patient } \\
\text { No. }\end{array}$ & Leg & $\begin{array}{c}\text { Overall } \\
\text { Correlation } \\
\text { Coefficient } \\
\text { with } \\
\text { Standard } \\
\text { curve } \\
\end{array}$ & $\begin{array}{c}\text { Correlation } \\
\text { Coefficient } \\
\text { at Stance } \\
\text { Phase }\end{array}$ & $\begin{array}{c}\text { Correlation } \\
\text { Coefficient } \\
\text { at Swing } \\
\text { Phase }\end{array}$ \\
\hline \multirow{2}{*}{$\begin{array}{c}\text { Patient- } \\
1\end{array}$} & Right & 0.854 & 0.98 & 0.80 \\
\hline & Left & 0.908 & 0.972 & 0.865 \\
\hline \multirow{2}{*}{$\begin{array}{c}\text { Patient- } \\
2\end{array}$} & Right & 0.771 & 0.961 & 0.7177 \\
\hline & Left & 0.5589 & 0.87 & 0.6646 \\
\hline \multirow{2}{*}{$\begin{array}{c}\text { Patient- } \\
3\end{array}$} & Right & 0.87 & 0.96 & 0.744 \\
\hline & Left & 0.778 & 0.979 & 0.63 \\
\hline \multirow{2}{*}{$\begin{array}{c}\text { Patient- } \\
4\end{array}$} & Right & 0.749 & 0.9785 & 0.647 \\
\hline & Left & 0.823 & 0.91 & 0.823 \\
\hline \multirow{2}{*}{$\begin{array}{l}\text { Patient- } \\
5\end{array}$} & Right & 0.86 & 0.95 & 0.756 \\
\hline & Left & 0.84 & 0.97 & 0.735 \\
\hline
\end{tabular}


From the data, it can be said that the stance phase not affected by the GBS as the values are in between 0.9-1. But the swing phase is very much deviated from the original graph pattern and the coefficient values are in between 0.6 to 0.8 . Due to the effect on swing phase the overall correlation coefficient is affected too. The problems which are found from this research are no heel strike on terminal swing phase, no foot movement on swing phase, no natural dorsiflexion operation on swing phase, long stance phase and small swing phase.

\section{Implementation of Automated AFO}

As there is no heel strike for the patient on terminal swing phase, they tend to drop toe/flat foot on the ground. But for the normal person gait, heel strike is a must. Also, at the beginning of initial swing, the dorsiflexion operation is done by TA muscle.
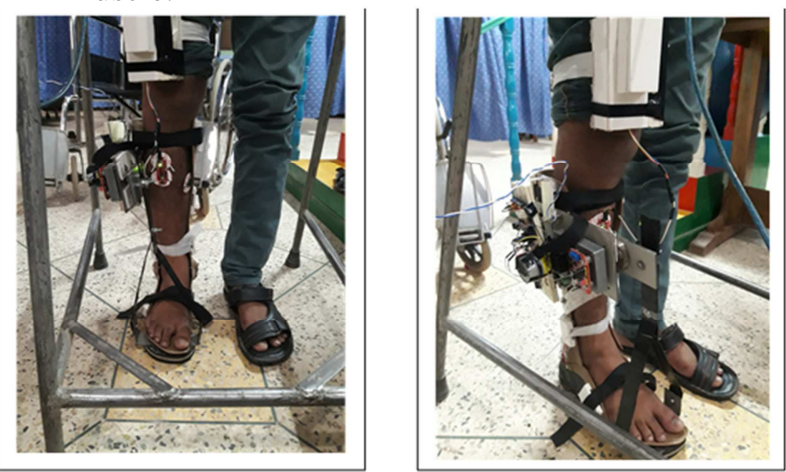

Fig. 9. Implementation of Automated AFO on GBS Patient

As the muscle is affected for GBS patients, they do not have natural dorsiflexion operation. So, the automated AFO provides both heel strike function and dorsiflexion operation to the GBS patient while walking. The device has been implemented on patients and also EMG signal is recorded simultaneously for performing the comparison with previous data. The automated AFO has been implemented on 2 patients to test the feasibility of the system in Fig.9.

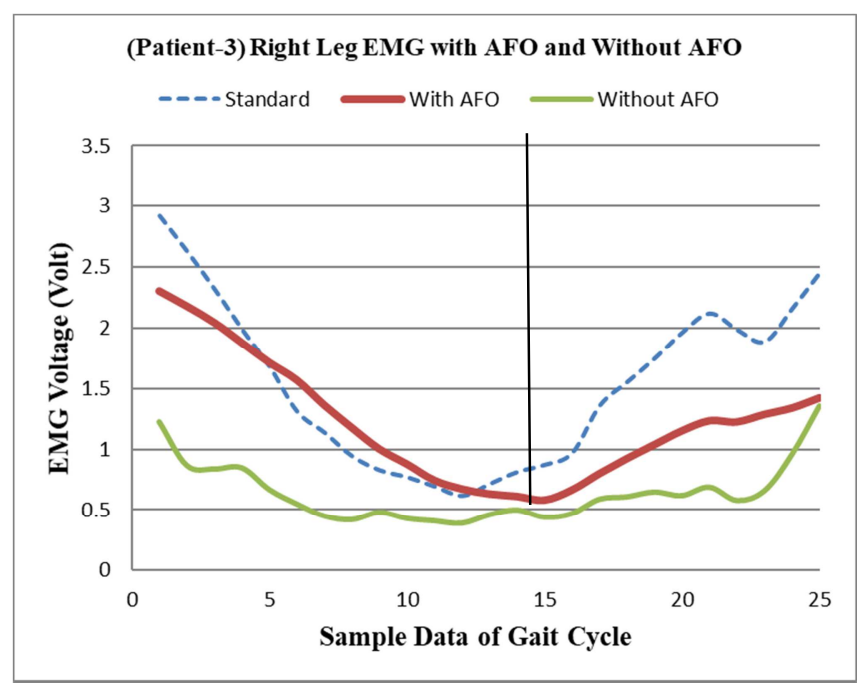

Fig. 10. (Patient-3) Right Leg EMG with AFO and Without AFO
(Patient-4) Right Leg EMG with AFO Vs. Without AFO

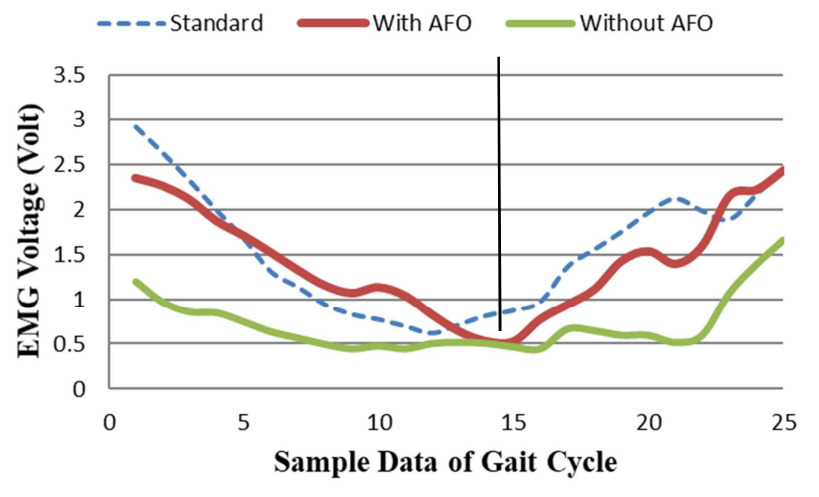

Fig. 11. (Patient-4) Right Leg EMG with AFO Vs. Without AFO

Fig. 10 and Fig. 11 show the gait EMG pattern of two patients both of using AFO and without AFO while walking where the patterns are quite close to the normal pattern. From the TABLE II, it is obtained that by using this automated AFO, the effect on swing phase has been lessened as the value of correlation coefficient increases. For that the value of overall gait cycle also increases. So, the improvements from this AFO implementation can be summarized as heel strike on terminal swing, dorsiflexion aid in swing phase, approximate natural swing phase length.

TABLE II

COMPARISON THE PATIENTS DATA (WITH AFO AND WITHOUT AFO)

\begin{tabular}{|c|c|c|c|c|}
\hline $\begin{array}{c}\text { Patient } \\
\text { No. }\end{array}$ & $\begin{array}{c}\text { AFO } \\
\text { Condition }\end{array}$ & $\begin{array}{c}\text { Overall } \\
\text { Correlation } \\
\text { Coefficient } \\
\text { with } \\
\text { Standard } \\
\text { curve }\end{array}$ & $\begin{array}{c}\text { Correlation } \\
\text { Coefficient } \\
\text { at Stance } \\
\text { Phase }\end{array}$ & $\begin{array}{l}\text { Correlation } \\
\text { Coefficient at } \\
\text { Swing Phase }\end{array}$ \\
\hline \multirow{2}{*}{$\begin{array}{c}\text { Patient- } \\
3\end{array}$} & $\begin{array}{c}\text { Without } \\
\text { AFO }\end{array}$ & 0.87 & 0.96 & 0.744 \\
\hline & With AFO & 0.91 & 0.95 & 0.909 \\
\hline \multirow{2}{*}{$\begin{array}{c}\text { Patient- } \\
4\end{array}$} & $\begin{array}{c}\text { Without } \\
\text { AFO }\end{array}$ & 0.749 & 0.9785 & 0.647 \\
\hline & With AFO & 0.89 & 0.943 & 0.857 \\
\hline
\end{tabular}

TABLE III

COMPARISON WITH OTHER DEVICES

\begin{tabular}{|c|c|c|c|c|}
\hline $\begin{array}{c}\text { Name of } \\
\text { the system }\end{array}$ & $\begin{array}{c}\text { Type of } \\
\text { device }\end{array}$ & $\begin{array}{c}\text { Type of } \\
\text { Patients }\end{array}$ & $\begin{array}{c}\text { Practical } \\
\text { Impleme- } \\
\text { ntation }\end{array}$ & $\begin{array}{c}\text { Automated } \\
\text { Angle }\end{array}$ \\
\hline Ref. [5] & $\begin{array}{c}\text { CAD } \\
\text { Model }\end{array}$ & $\begin{array}{c}\text { Cerebral } \\
\text { Palsy }\end{array}$ & No & No \\
\hline Ref. [6] & $\begin{array}{c}\text { Rubber } \\
\text { Splint }\end{array}$ & $\begin{array}{c}\text { Common } \\
\text { foot drop }\end{array}$ & Yes & No \\
\hline Ref. [7] & Strip Built & $\begin{array}{c}\text { Common } \\
\text { foot drop }\end{array}$ & Yes & No \\
\hline Ref. [11] & $\begin{array}{c}\text { Force } \\
\text { sensor } \\
\text { device }\end{array}$ & $\begin{array}{c}\text { Hemiplegia } \\
\text { foot drop }\end{array}$ & No & Yes \\
(Proposed) \\
\hline Ref. [12] & $\begin{array}{c}\text { Oil damper } \\
\text { Joint }\end{array}$ & Stroke & $\begin{array}{c}\text { Yes } \\
\text { (Proto- } \\
\text { type) }\end{array}$ & No \\
\hline
\end{tabular}




\begin{tabular}{|c|c|c|c|c|}
\hline Ref. [14] & $\begin{array}{c}\text { CAD } \\
\text { Model }\end{array}$ & $\begin{array}{c}\text { Common } \\
\text { foot drop }\end{array}$ & No & No \\
\hline Ref. [15] & $\begin{array}{c}\text { Stretching } \\
\text { machine }\end{array}$ & $\begin{array}{c}\text { Equino- } \\
\text { varus }\end{array}$ & Yes & Yes \\
\hline Ref. [16] & $\begin{array}{c}\text { Pressure } \\
\text { Sensor }\end{array}$ & $\begin{array}{c}\text { FES-aided } \\
\text { Gait } \\
\text { Training }\end{array}$ & No & No \\
\hline Ref.[17] & $\begin{array}{c}\text { CAD } \\
\text { Model }\end{array}$ & $\begin{array}{c}\text { Flaccid } \\
\text { Paretic }\end{array}$ & No & No \\
Proposed \\
$\begin{array}{c}\text { Impleme } \\
\text { nted AFO }\end{array}$ & $\begin{array}{c}\text { Seel Force } \\
\text { Sensitive } \\
\text { Servo } \\
\text { Motor } \\
\text { Based }\end{array}$ & $\begin{array}{c}\text { Guillain- } \\
\text { Barré } \\
\text { Syndrome } \\
\text { (GBS) }\end{array}$ & $\begin{array}{c}\text { Yes } \\
\text { (On } \\
\text { patient) }\end{array}$ & Yes \\
\hline
\end{tabular}

From the TABLE III, it can be noticed that the development of AFO has started in recent years and researchers all around the world have been trying to develop with different features. Some of them have developed and designed for common foot drop but the complexities of different types of drop foot patients are different in many aspects. So, those designs can not be implemented on patients directly. But our proposed AFO has been especially designed for GBS patients by considering every criterion of them. In recent days, the L-shaped fixed AFO are normally used by patients to avoid the foot drop complexities. For GBS patients, it becomes much more difficult to use these fixed AFOs. But, after analyzing the real-life GBS patients and their walking patterns, this automated AFO has been designed and implemented to those patients for assisting them during walking. From the given data in TABLE I and TABLE II, the improvements can be identified by using this automated AFO during walking as correlation coefficient value in swing phase has improved from $0.6-0.74$ to 0.85 0.90 which represents the patients are walking like normal pattern instead of their inability to raise their toes during swing phase. In automated AFO, the motorized system assists them to raise their toes and maintain almost normal walking pattern where normal AFO does not provide this upright movement support rather holding the toes only.

\section{CONCLUSION}

To sum up all, this AFO should be used by patient on regular basis while they exercise to walk on their assessment period. As this device helps to maintain natural pattern of gait by providing the support both in stance phase and swing phase in gait cycle during walking where the fixed or conventional AFO just provide support only on stance phase, the regular use of this automated AFO on patient's (GBS) exercises can facilitate their recovery process as well as recovery time. As the automated AFO is succeeding to aid the GBS patient gait, this device can be further improved to make it more patient friendly. As the structural weight is little high of this AFO, the proper structural design can be modified to make this AFO less weight for the regular use purpose. In this project, only right leg AFO has been developed and implemented. In future, the both leg AFO can be developed and the results should be compared and this device will be converted into more compact form for easier use of GBS patients.

\section{ACKNOWLEDGMENT}

We would like to show our heartiest gratitude to the Center for Rehabilitation of Paralyzed (CRP) for collaborating with Chittagong University of Engineering and Technology and providing necessary patients and their assenment details for conducting the research. The reference no. of this project is CRP-R\&E-0401-21. We would also like to thank the department of EEE, CUET for providing the laboratory support while conducting this research.

\section{REFERENCES}

[1] "Guillain-Barré Syndrome Fact Sheet" Niams, June 1, 2016. (Retrieved on May 2018).

[2] J. J. Sejvar et al. "Population incidence of Guillain-Barré syndrome: a systematic review and meta-analysis", Neuroepidemiology, 2011, Page 123-133.

[3] N. Yuki et al."Guillain-Barré Syndrome", New England Journal of Medicine, 2012, Page 2294-2304.

[4] S. R. Whiteside et al. "Practice analysis of certified practitioners in the disciplines of orthotics and prosthetics" American Board for Certification in Orthotics and Prosthetics, Inc., Alexandria, Virginia, 2007.

[5] M.L. Jain et al. "Virtual modeling of an ankle foot orthosis for correction of foot abnormality. Robotics and Computer-Integrated Manufacturing, Volume 27, Issue 2, 2011, Page 257-260.

[6] V. Jain et al. "Catapult splint: A foot dorsiflexion assist splint" Foot and Ankle Surgery, Volume 17, Issue 4, 2011, Page 312-314.

[7] M. A. de Souza et al. "Beneficial effects of ankle-foot orthosis daytime use on the gait of Duchenne muscular dystrophy patients" Clinical Biomechanics, 2016, Page 102-110.

[8] J.M.A. Whitehead et al. "Stair ascent and descent biomechanical adaptations while using a custom ankle-foot orthosis" Journal of Biomechanics, Volume 49, Issue 13, 2016, Page 2899-2908.

[9] C. Ranz et al. "The influence of passive-dynamic ankle-foot orthosis bending axis location on gait performance in individuals with lowerlimb impairments", Clinical Biomechanics, 2016, Page 13 -21.

[10] J. Romkes and R. Brunner, "Comparison of a dynamic and a hinged ankle-foot orthosis by gait analysis in patients with hemiplegic cerebral palsy", Gait and Posture, 2002, Page 18-24.

[11] A. Hamid et al. "Force Sensor Detection and Performance Evaluation of New Active System Ankle Foot Orthosis" Procedia Engineering, Volume 41, 2012, Page 510-515.

[12] T. Kobayashi et al. "Design of a stiffness-adjustable ankle-foot orthosis and its effect on ankle joint kinematic s in patients with stroke", Gait \& Posture, 2011, Page 721-723.

[13] J. J. Bregman et al. "Polypropylene ankle foot orthoses to overcome drop-foot gait in central neurological patients: A mechanical and functional evaluation" Prosthetics and Orthotics International, 2010, Page 293-304.

[14] C. Zhanga, et al. "Design of a quasi-passive 3 DOFs ankle-foot wearable rehabilitation orthosis." Bio-Medical Materials and Engineering, 2015, Page 647-654.

[15] T. Kimura et. al "Ankle stretching rehabilitation machine for equinovarus: Automation of eversion and flexion control", 2017 IEEE International Conference on Systems, Man, and Cybernetics (SMC) Banff Center, Banff, Canada, October 5-8, 2017, Page 26962700.

[16] E. Y. Lee et. al "Design of a Pressure Sensitive Ankle-Foot Orthosis for FES-aided Gait Training", ICIIBMS 2017, Track 2: Artificial Intelligence, Robotics and Human-Computer Interaction, Okinawa, Japan, 2017, Page-243-244.

[17] D. Wilk et. al "Development of an Ankle-Foot Orthosis That Provides Support for Flaccid Paretic Plantar flexor and Dorsiflexor Muscles", IEEE Transactions on Neural Systems and Rehabilitation Engineering, 2018. 